\title{
Lusioersily
}

\section{A Longitudinal Analysis of Estimation, Counting Skills, and Mathematical Ability Across the First School Year}

Muldoon, K., Towse, J., Simms, V., Perra, O., \& Menzies, V. (2012). A Longitudinal Analysis of Estimation,

Counting Skills, and Mathematical Ability Across the First School Year. Developmental Psychology, 49(2), 250258.

Link to publication record in Ulster University Research Portal

Published in:

Developmental Psychology

Publication Status:

Published (in print/issue): 17/02/2012

\section{Document Version}

Publisher's PDF, also known as Version of record

\section{General rights}

Copyright for the publications made accessible via Ulster University's Research Portal is retained by the author(s) and / or other copyright owners and it is a condition of accessing these publications that users recognise and abide by the legal requirements associated with these rights.

\section{Take down policy}

The Research Portal is Ulster University's institutional repository that provides access to Ulster's research outputs. Every effort has been made to ensure that content in the Research Portal does not infringe any person's rights, or applicable UK laws. If you discover content in the Research Portal that you believe breaches copyright or violates any law, please contact pure-support@ulster.ac.uk. 


\section{Journal of Cross-Cultural Psychology \\ http://jcc.sagepub.com/}

Cross-Cultural Comparisons of 5-Year-Olds' Estimating and Mathematical Ability

Kevin Muldoon, Victoria Simms, John Towse, Victoria Menzies and Guoan Yue Journal of Cross-Cultural Psychology published online 28 April 2011

DOI: $10.1177 / 0022022111406035$

The online version of this article can be found at:

http://jcc.sagepub.com/content/early/2011/04/26/0022022111406035

\section{Published by: \\ (S)SAGE}

http://www.sagepublications.com

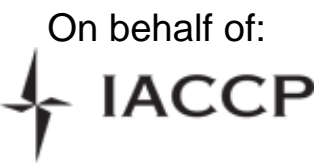

International Association for Cross-Cultural Psychology

Additional services and information for Journal of Cross-Cultural Psychology can be found at:

Email Alerts: http://jcc.sagepub.com/cgi/alerts

Subscriptions: http://jcc.sagepub.com/subscriptions

Reprints: http://www.sagepub.com/journalsReprints.nav

Permissions: http://www.sagepub.com/journalsPermissions.nav 


\section{Cross-Cultural Comparisons of 5-Year-Olds' Estimating and Mathematical Ability}

Journal of Cross-Cultural Psychology $X X(X) 1-13$

(c) The Author(s) 2011

Reprints and permission:

sagepub.com/journalsPermissions.nav DOI: 10.1 1 77//0022022 III406035 jccp.sagepub.com

\section{(S)SAGE}

\title{
Kevin Muldoon', Victoria Simms², John Towse ${ }^{3}$, Victoria Menzies, and Guoan Yue ${ }^{5}$
}

\begin{abstract}
Recent research suggests that both the accuracy and linearity of number estimations are a source of difficulty in mathematical learning. There is also a range of evidence to suggest that children in East Asia are typically mathematically precocious compared to Western peers. Bringing these strands of work together, we discuss number line estimations involving an ability match study of children growing up in the United Kingdom and China. This article confirms that the quality of children's number estimation is associated with some-but by no means all-early number problems. However, contrary to earlier studies, young Chinese children do not display more linear number scales in advance of (and potentially as a driver for) their math skills. Instead, their number estimations are not more accurate than those from an older Western sample with equivalent mathematical ability. The development of linearity in numerical representations takes a complex developmental path in multiple cultures.
\end{abstract}

\section{Keywords}

Number; Estimating; Mathematics; Preschool

\section{Introduction}

Grasping the cognitive underpinnings of arithmetic and mathematics entails the gradual assembly of a complex suite of concepts and procedural skills. Central to these early developments is the way children treat the meaning of number words and use these words when faced with questions about numerosity. Recent findings have brought attention to the possibility that erroneous mental representations of number words may affect mathematics learning during, and even prior to, schooling (Siegler \& Mu, 2008). This conclusion is based on the discovery that the quality of children's estimations on a number line predicts how well they perform on mathematics problems (Booth \& Siegler, 2006; Geary, Bailey, \& Hoard, 2009; Siegler \& Mu, 2008).

\footnotetext{
'Heriot Watt University, Edinburgh, UK

${ }^{2}$ Queens University, Belfast, UK

${ }^{3}$ Lancaster University, Lancaster, UK

${ }^{4}$ University of York, Heslington, UK

${ }^{5}$ Nankai University, Tianjin, China

Corresponding Author:

Kevin Muldoon, School of Life Sciences, Heriot-Watt University, Edinburgh, EHI4 4AS, UK.

Email: k.muldoon@hw.ac.uk
} 
Numerical estimations appear to draw on conceptions of number that correspond to a mental number scale, and there is broad agreement that, at least for nonsemitic languages, this number scale is akin to a left-to-right "ruler," with zero lying at the leftmost point (see Dehaene, 1997; Fischer, 2003). In childhood the mental scale to which magnitude codes are aligned is compressed; in particular, representations are thought to be logarithmic rather than linear with respect to numerals of different magnitude (Booth \& Siegler, 2006; Siegler \& Opfer, 2003). According to the account developed by Siegler and Opfer (2003), over time, our mental "number scale" becomes less compressed and more accurate. The "de-compression" of the mental number scale appears to take place roughly between the ages of 5 and 8 , at least for numbers between 0 and 100 (Booth \& Siegler, 2008). Subsequent studies have offered alternative accounts of why young children's numerical estimations may not be linear and which do not posit a logarithmic scale per se (Ebersbach, Luwel, Frick, Onghena, \& Verschaffel, 2008; Nuerk, Kaufmann, Zoppoth, $\&$ Willmes, 2004). Crucially, however, these theoretical alternatives still acknowledge that children have representations across the scale range that are markedly different from adults and not well captured by a single linear function.

Booth and Siegler (2006) have suggested nonlinear representations might be a source of difficulty in mathematical learning following the discovery that the quality of estimations on a number line task correlates with the ability to carry out simple addition problems (Siegler \& $\mathrm{Mu}$, 2008). These correlations raise the concern that the slow development of accurate, linear representations might constrain mathematics learning. For example, children who estimate on a logarithmic scale might think that 20 is midway between 0 and 100. Accordingly, these children would be disadvantaged when presented with any mathematical test requiring a conceptualization of relative number. Even simple numerical problems that children encounter before they begin school both inform and tap into their understanding of written and verbal number codes (e.g., "How many dwarves are around Snow White's bed?"). Siegler and Opfer's (2003) discovery that even 2 years after starting school, North American children apparently refer to a mental number scale with logarithmic variability when estimating quantity, is potentially of great importance.

\section{Cross-Cultural Perspectives on Number Estimation}

Siegler and $\mathrm{Mu}$ (2008) reported that Chinese children's number line estimates were comparable to significantly older U.S. children. Given the argument above, this might explain why Asian children have an early mathematical advantage over their North American peers (Stevenson, Chen, \& Lee, 1993; see also Towse \& Saxton, 1998). Siegler and Mu (2008) compared children from China and the United States using a number line estimation task alongside two-digit addition problems where the sum was less than 10 (e.g., $3+5)$. They found that Chinese children's estimations were more linear and more accurate and that greater linearity and accuracy were associated with better performance on the addition problems. Moreover, there was a strong relationship between math performance and the linearity of estimations among the U.S. sample ( $r=$ $.60)$ with a more modest but still significant relationship for the Chinese sample $(r=.27)$.

Siegler and $\mathrm{Mu}$ find an advantage for Chinese children on not only familiar tasks like adding two numbers together but also unfamiliar number tasks. This would be consistent with the hypothesis that children's internal number line contributes to individual differences in math performance. Siegler and $\mathrm{Mu}$ (2008) were careful not to conclude that there is a necessary causal link between number representations and arithmetic skill. Nonetheless, this combination of convergent evidence from within and between national groups promotes the idea that number line estimation may be an important marker of numerical thinking.

This leads to the question of how far nonlinear representation of number affects performance on a range of numerical and mathematical tasks. If nonlinearity is an impediment to mathematical 
progress at a particular age, it is imperative that it be identified as such before expending effort on addressing the question of how the problems posed by logarithmic representations might be overcome in the classroom.

\section{The Present Study}

The present study extends the work to date in three ways. First, it explores the association between estimation and math ability using a broader index of numerical problems. Second, it compares associations between math ability and a range of number line scales. Third, it uses an ability matching design to test for cross-cultural differences in estimation skill.

Math ability. The British Ability Scales' (BAS) "Early Number Concepts" battery is used with children between 2:6 and 7:11 years of age. It assesses skills such as reciting number words, counting objects, classifying and matching sets by numerosity, recognizing ordinal relationships, and solving basic addition and subtraction problems. A raw score (the number of correct responses) can be translated into an ability score (which reflects both the raw score and the difficulty of the items answered correctly) and a percentile score, which can be compared to the distribution of children of the same age in the BAS standardized sample.

Using different number line scales. The extant literature focuses on small ( 0 to 10$)$, large (0 to 100$)$, or very large $(0$ to 1,000$)$ number line scales. Number line estimation between 0 and 100 has been linked with math achievement in the early school years (Booth \& Siegler, 2006), but schoolchildren initially learn about mathematics using a much smaller range of numbers. When starting school, children in Europe and the United States are expected to be familiar with numbers up to 10, are likely to have less experience dealing with numbers between 10 and 20, and are in the process of being introduced to numbers up to 100 . Given that children display linear representations on smaller number lines before they do the same on larger number lines, it is informative to consider how mathematical skills are linked to number estimation across a variety of scale magnitudes.

Cross-cultural matching. Siegler and Mu (2008) compared children from the United States and China using an age-match design, reporting the relatively advanced numeric skills of the latter sample. Our approach is somewhat different but complementary. Our cross-national samples were designed to be matched on mathematical ability (as assessed by the BAS). An ability match design is an important investigative technique that has been successfully exploited in the domain of reading (Bradley \& Bryant, 1978; Cain, Oakhill, \& Bryant, 2000) and mathematical cognition (Torbeyns, Verschaffel, \& Ghesquière, 2004a, 2004b). The essence of the rationale is as follows: In an age-match design, a group difference in number estimation skill might be interpreted in terms of a relative developmental delay in the acquisition of linear/more accurate representations or in terms of the possibility that number representations constrain mathematical cognition. A math ability match design indicates whether estimation skills are different even when one controls for mathematics performance.

\section{Method}

\section{Participants}

We recruited a total of 188 children; 85 Chinese children (mean age $=54$ months, range $=47$ to 62 months; 39 girls) from three kindergartens in Tianjin and 103 Scottish children (mean age = 64 months, range $=57$ to 70 months; 50 girls) from five elementary schools in Edinburgh. All children were able to count up to 10 and had been introduced to numbers up to 100 . We initially collected the data from the Scottish children, and sampling 28 Chinese children indicated a good 
math ability match. Accordingly, we recruited more Chinese children from the same age range but then found that the full cohorts no longer matched on their BAS scores. Consequently, we ran two sets of comparisons. First, we compared all 103 Scottish and all 85 Chinese children, then produced two BAS-matched samples (Chinese ${ }_{\text {BAS-match }}$ and Scottish $\left._{\text {BAS-match }}\right)$, each with 58 children.

\section{Materials and Procedure}

Number estimation task. Three number lines were used: 0 to 10, 0 to 20, and 0 to 100 . Children received the problems in three blocks of trials presented in the same order to every child -0 to 10 first and 0 to 100 last - but ordering of trials was randomized within blocks. For each block, children were first given an orientation test. The experimenter showed the child a line $(25 \mathrm{~cm}$ long) with 0 at the left end and 10 at the rightmost end and told why these numbers were there. The experimenter then showed where " 5 " would sit on the line, explaining that it goes in the middle because it is half way between 0 and 10 . This was repeated using " 10 " on the 0 to 20 line and " 50 " on the 0 to 100 line for Blocks 2 and 3. Thus, each child received a total of 34 experimental problems. On each problem, children were presented with a separate sheet of paper with either a 0 to 10,0 to 20 , or 0 to 100 , number line across the middle and asked to mark the line where a given number (shown near the top of the page and verbalized by the experimenter) would go. The numbers to be estimated and marked on the lines were $1,2,3,4,6,7,8$, and 9 (on a 0 to 10 line); $3,4,6,8,12,14,17$, and 18 (on a 0 to 20 line); and $3,4,6,8,12,14,17,18,21,24,25$, $29,33,39,42,48,52,57,61,64,72,79,81,84,90$, and 96 (on a 0 to 100 line).

Mathematics achievement. The 24 number problems were drawn from the Early Number Concepts battery of the BAS and included questions that assess the following:

1. Recognizing number names and numerals (e.g., "Point to the person who has 3 boxes").

2. Identifying quantitative relationships (less than/more than/same as) (e.g., "Two of these people have the same number of boxes. Point to those two people.").

3. Matching corresponding magnitudes (continuous quantity) (e.g., [Gesturing to a mixed array of small and large spades] "Show me the buckets that go with the little spades").

4. Matching sets of discontinuous quantity (e.g., [Pointing to the yellow ladybird with four dots] "Find the red ladybirds that go with this one.").

5. Solving basic addition and subtraction word problems (e.g., "John [shown clutching balloons in each hand] is going to give all his balloons to Lisa. How many will she have then?").

\section{Results}

\section{All Children}

Number estimation task. For each child we calculated their percent absolute error (PAE) on each target number using the formula: PAE $=$ [estimated value - number to be estimated $] /$ number line scale]. For example, if the task was to estimate where 8 would fall on the 0 to 10 number line and a child made a mark at the point on the line corresponding to 6 , their PAE would be $[6-8] / 10=$ $-0.20(20 \%)$. From these calculations, each nationality's mean PAE for the three number lines was derived (see Table 1). Consistent with procedures in other estimation research, the PAE data were arcsine transformed.

The Scottish children were more accurate than the Chinese on the 0 to 10 number line, $t(186)=$ $-5.96, p<.001$, and on the 0 to 20 number line, $t(186)=-7.24, p<.001$, but not on the $0-100$ line, ${ }^{1} t(161)=-.215, p>.10$. The mean slope values of the Scottish estimates were consistently 
Table I. PAE, Slope Values, $R_{\text {lin }}^{2}$ and $R_{\text {log }}^{2}$ on Each Number Line for All Children

\begin{tabular}{|c|c|c|c|c|c|c|}
\hline \multirow[b]{2}{*}{ Number Line } & \multicolumn{3}{|c|}{ Scottish } & \multicolumn{3}{|c|}{ Chinese } \\
\hline & $0-10$ & $0-20$ & $0-100$ & $0-10$ & $0-20$ & $0-100$ \\
\hline \multicolumn{7}{|c|}{ (a) Analysis of individual children's estimates (mean values) } \\
\hline PAE & .17 & .15 & .31 & .25 & .25 & .32 \\
\hline Slope & .91 & .84 & .35 & .38 & .24 & .21 \\
\hline$R^{2}$ & .76 & .69 & .27 & .49 & .41 & .24 \\
\hline$R^{\operatorname{lin}}$ & .64 & .74 & .46 & .47 & .42 & .31 \\
\hline \multicolumn{7}{|c|}{ (b) Analysis by group (median values) } \\
\hline$R^{2}$ & .94 & .94 & .45 & .94 & .90 & .38 \\
\hline$R_{\log }^{2^{\operatorname{lin}}}$ & .76 & .99 & .80 & .88 & .97 & .66 \\
\hline
\end{tabular}

Note: PAE = percent absolute error.

Table 2. PAE, Slope Values, $R_{\text {lin }}^{2}$ and $R_{\text {log }}^{2}$ on each Number Line for BAS-Matched Samples

\begin{tabular}{|c|c|c|c|c|c|c|}
\hline \multirow[b]{2}{*}{ Number Line } & \multicolumn{3}{|c|}{ Scottish $_{\text {BAS-match }}$} & \multicolumn{3}{|c|}{ Chinese $_{\text {BAS-match }}$} \\
\hline & $0-10$ & $0-20$ & $0-100$ & $0-10$ & $0-20$ & $0-100$ \\
\hline \multicolumn{7}{|c|}{ (a) Analysis of individual children's estimates (mean values) } \\
\hline PAE & .17 & .14 & .31 & .23 & .24 & .32 \\
\hline Slope & .90 & .82 & .15 & .47 & .33 & .27 \\
\hline$R^{2}$ & .78 & .71 & .29 & .54 & .45 & .24 \\
\hline$R_{\log }^{\operatorname{lin}}$ & .47 & .42 & .32 & .52 & .46 & .33 \\
\hline \multicolumn{7}{|c|}{ (b) Analysis by group (median values) } \\
\hline$R^{2}$ & .94 & .94 & .48 & .97 & .89 & .25 \\
\hline$R_{\log }^{\operatorname{lin}^{2}}$ & .75 & .98 & .80 & .93 & .95 & .54 \\
\hline
\end{tabular}

Note: $\mathrm{PAE}=$ percent absolute error; $\mathrm{BAS}=$ British Ability Scales.

closer to 1.00 than the Chinese estimates; on the 0 to 10 line, $t(186)=8.71, p<.01$, on the 0 to 20 line, $t(186)=10.147, p<.01$, and on the 0 to 100 line, $t(161)=1.974, p=.05$. Including BAS ability score or age (in months) as a covariate failed to change five of these six effects (all $p$ values $<.01$ ), the exceptions being that there was no longer an effect of nationality on slope values on the 0 to 100 scale when including ability score $(p=.27)$ or age $(p=.36)$ as a covariate.

Next, we calculated the amount of explained variance in the estimates for each number line in two ways. First, we calculated each individual's $R_{l i n}^{2}$ and $R_{\text {log }}^{2}$ (the variance in a set of estimates accounted for by fitting linear and logarithmic functions) on each number line. Second, we used the estimates from every group member for each target number on a number line and used the median values to calculate each group's $R_{\text {lin }}^{2}$ and $R_{\text {log }}^{2}$. Table 1 reports both sets of scores.

National differences in mean $R_{\text {lin }}^{2}$. Following arcsine transformation, the variance accounted for by the linear function was greater for the Scottish children than the Chinese on the 0 to 10 number line, $t(186)=5.38, p<.001$, and the 0 to 20 line, $t(186)=5.70, p<.001$. However, there was no significant difference on the 0 to 100 number line. As for PAE and Slope analyses above, these effects held after entering the BAS ability score and age (in months) as separate covariates.

Association between number line estimation and mathematics skill. Comparing BAS values revealed that the Scottish children $(M=133)$ outperformed the Chinese children $(M=121), t(187)=4.66$, 
Table 3. Correlations Between BAS Ability Score and Group Linearity $\left(R^{2}{ }_{\text {lin }}\right)$ on Each Number Line by Nationality

\begin{tabular}{lccc}
\hline Number Line & Scottish & Chinese & Chinese $_{\text {BAS-match }}$ \\
\hline 0 to 10 & .15 & $.40^{* *}$ & $.39^{* *}$ \\
0 to 20 & $.31^{* *}$ & $.34^{* *}$ & $.34^{*}$ \\
0 to 100 & $.35^{* *}$ & .16 & .27 \\
\hline
\end{tabular}

Note: $\mathrm{BAS}=$ British Ability Scales

$*_{p}<.05$. **p $<.01$.

$p<.01$. It should be remembered that the Scottish children were on average 10 months older than the Chinese. However, the mean for the Scottish children falls in the 38th percentile while the Chinese mean score falls in the 53rd percentile. So taking age into account, the Chinese cohorts can be said to be developmentally more advanced than the Scottish cohort in terms of ability. What is striking - with respect to previous literature that finds Chinese children far in advance of North American children-is that the Chinese cohort is normal when set against the BAS standardized sample scores of children from the United Kingdom.

Table 3 reports children's performance on the BAS test correlated with the group's linear function $\left(R^{2}{ }_{\operatorname{lin}}\right)$. Of particular interest, the correlation for the Scottish children on the 0 to 100 number line is much lower than that found by Siegler and Mu (2008), even though they are on average only 3 months younger. We suspect the key difference lies in the assessment of mathematical competence. While Siegler and Mu used a single, time-limited question, we administered 24 untimed questions across five subcategories. The nonsignificant correlation for the Chinese group suggests that, for 4-year-olds, nonlinearity on the large 0 to 100 scale is unlikely to act as a constraint on their ability to solve age-appropriate number problems in the way that nonlinearity on the 0 to 10 and 0 to 20 scales might. Modest but statistically significant correlations were obtained on the 0 to 20 scale (Scottish and Chinese children) and 0 to 10 scale (Chinese only).

We repeated the correlations but replaced linearity with PAE (see Table 4). This confirmed that BAS scores are also associated with how accurate children's estimates are on the 0 to 20 and 0 to 100 number lines.

One of the aims of the present study, however, was to examine whether estimation skills are associated with all domains of mathematics achievement or whether specific subskills are more reliant than others on number representations. Accordingly, we divided the BAS questions into five subcategories described above. The mean scores in each subcategory and the correlations between each subcategory and linearity of estimations are reported in Tables 5 and 6 . The linearity of children's estimations was most consistently correlated with problems where children had to match quantities with symbols ("Recognizing numerals") and problems where the child had to select a set of items that was one more than/one less than/same as a known quantity. These correlations were significant for both cohorts on all number lines except 0 to 10 . The picture is less clear for the other three categories.

We checked whether the mean overall advantage the Scottish children displayed on the BAS as a whole was due to better performance on specific types of questions, but this was not the case. A series of $t$ test comparisons revealed the advantage the Scottish children display on the overall ability score was reflected in each of the five subcategories; all $t$ tests were significant at the $5 \%$ level.

Examining the estimation data for bi-linear function fits. We explored deviations in estimations from linearity in more detail, given recent suggestions that bi-linear rather than logarithmic accounts 
Table 4. Correlations Between BAS Ability Score and PAE on Each Number Line by Nationality

\begin{tabular}{lllc}
\hline Number Line & Scottish & Chinese & Chinese $_{\text {BAS-match }}$ \\
\hline 0 to 10 & -.06 & $-.31^{* *}$ & $-.27^{*}$ \\
0 to 20 & $-.39 * *$ & $-.27^{*}$ & -.22 \\
0 to 100 & $-.27^{* *}$ & -.23 & .31 \\
\hline
\end{tabular}

Note: $\mathrm{PAE}=$ percent absolute error; BAS $=$ British Ability Scales.

$*_{p}<.05$. **p $<.01$.

Table 5. Mean Scores Across 5 Subscales of the BAS

\begin{tabular}{lccccc}
\hline $\begin{array}{l}\text { Problem } \\
\text { Nationality }\end{array}$ & $\begin{array}{c}\text { Recognize } \\
\text { Numerals }\end{array}$ & $\begin{array}{c}\text { Identify } \\
\text { Ordinal } \\
\text { Relations }\end{array}$ & $\begin{array}{c}\text { Matching } \\
\text { Continuous } \\
\text { Quantity }\end{array}$ & $\begin{array}{c}\text { Matching } \\
\text { Discontinuous } \\
\text { Quantity }\end{array}$ & $\begin{array}{c}\text { Adding / } \\
\text { Subtracting }\end{array}$ \\
\hline Scottish & 3.05 & 2.71 & 4.56 & 2.99 & 1.53 \\
Chinese & 2.48 & 2.18 & 4.09 & 2.52 & 1.18 \\
Scottish $_{\text {BAS-match }}$ & 2.96 & 2.70 & 4.65 & 2.89 & 1.53 \\
Chinese $_{\text {BAS-match }}$ & 2.76 & 2.41 & 4.81 & 2.79 & 1.28 \\
\hline
\end{tabular}

Note: BAS $=$ British Ability Scales.

Table 6. Correlations Between Each $R_{\text {lin }}^{2}$ and the Five BAS Subcategories

\begin{tabular}{|c|c|c|c|c|c|c|c|c|c|}
\hline \multirow[b]{2}{*}{ Number Line } & \multicolumn{3}{|c|}{ Scottish } & \multicolumn{3}{|c|}{ Chinese } & \multicolumn{3}{|c|}{ Chinese $_{\text {BAS-match }}$} \\
\hline & $0-10$ & $0-20$ & $0-100$ & $0-10$ & $0-20$ & $0-100$ & $0-10$ & $0-20$ & $0-100$ \\
\hline \multicolumn{10}{|l|}{ BAS subcategory } \\
\hline Recognize numerals & .02 & $.20^{*}$ & $.24 *$ & $.39 * *$ & $.45^{* *}$ & $.36^{* *}$ & $.44 * *$ & $.38^{* *}$ & .30 \\
\hline Identify ordinal relations & .16 & $.30 * *$ & $.33 * *$ & $.37^{* *}$ & $.38 * *$ & $.50 * *$ & $.44 * *$ & $.32 *$ & $.50 * *$ \\
\hline Matching continuous quantity & .09 & $.20^{*}$ & $.21^{*}$ & .18 & .16 & .06 & .07 & .10 & .17 \\
\hline Matching discontinuous quantity & .06 & $.35 * *$ & $.29 * *$ & $.29 *$ & $.23 *$ & .16 & $.26 *$ & .15 & .17 \\
\hline Adding sets & .11 & .09 & .18 & $.23^{*}$ & $.37 * *$ & $.31^{*}$ & .25 & $.28 *$ & .23 \\
\hline
\end{tabular}

Note: BAS = British Ability Scales.

$* p<.05 . * * p<.01$.

are preferable. Indeed, Figure 1 suggested that two linear functions with different slope values might fit the plots on the 0 to 100 scale and possibly 0 to 20 scale. We used SegReg (Oosterbaan, n.d.) to identify a possible breakpoint in the data. For the Scottish data, no breakpoints were found on the 0 to 10 or 0 to 20 scales. However, a breakpoint around 15 was found on the 0 to 100 scale, with the best fitting function involving a slope of 5.13 on numbers up to 15 and a slope of 0.11 thereafter. The Chinese data yielded similar results, with no breakpoint found on the 0 to 10 scale and a breakpoint around 15 on the 0 to 100 scale (slope values of 2.15/0.06). However, there was an identified breakpoint around 7 on the 0 to 20 scale for the Chinese cohort, with slope values of 1.22 and 0.31 . The difference in slope values on the 0 to 100 scale in particular suggests that children's representations of number are linearly spaced (albeit inaccurately, resulting in a steep 

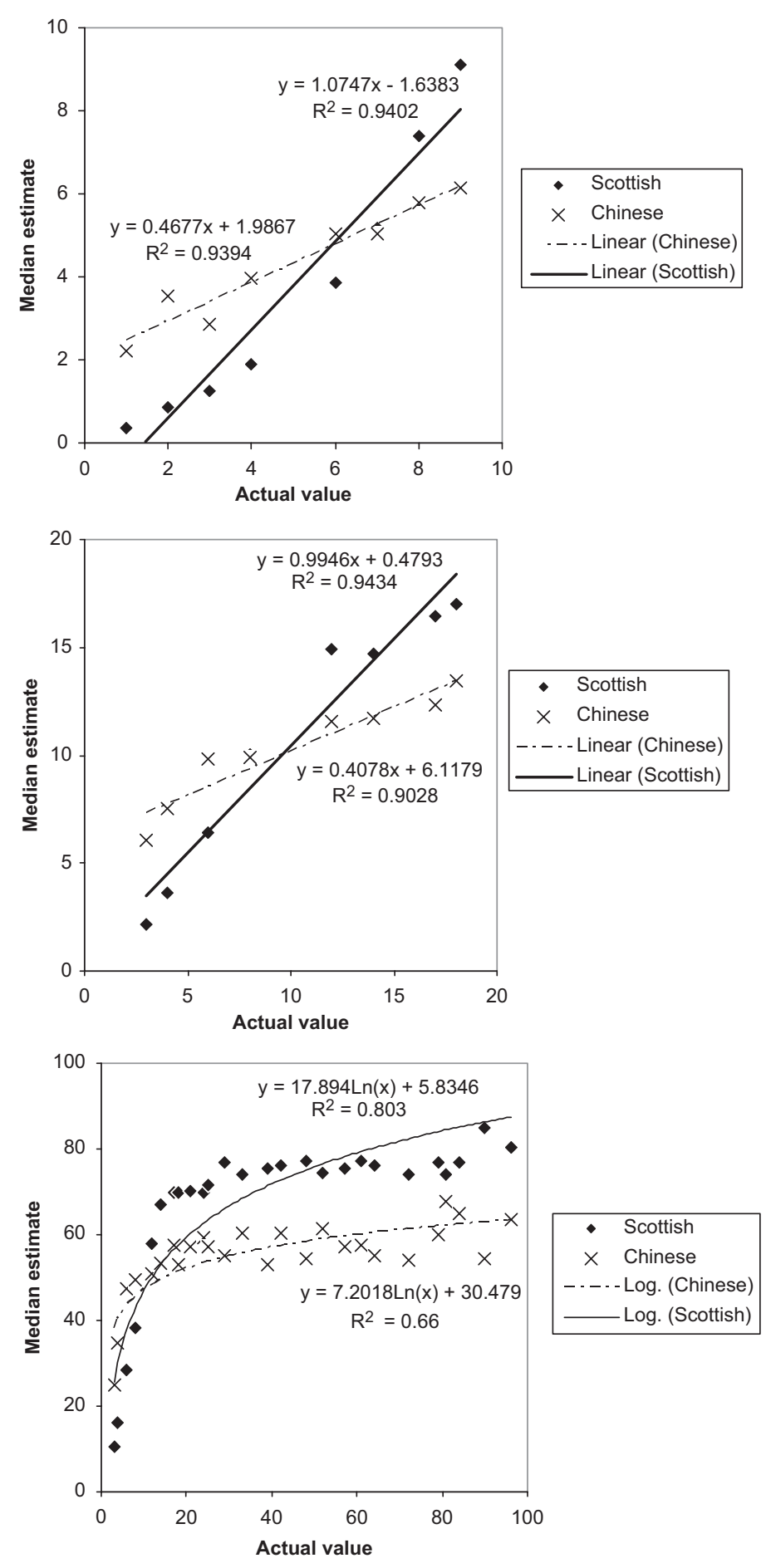

Figure I. U.K. and Chinese (Full Sample) Median Estimates for 0 to I0, 0 to 20, and 0 to 100 Number Lines Showing Linear (0 to 10,0 to 20) and Logarithmic (0 to 100) Function Fits 


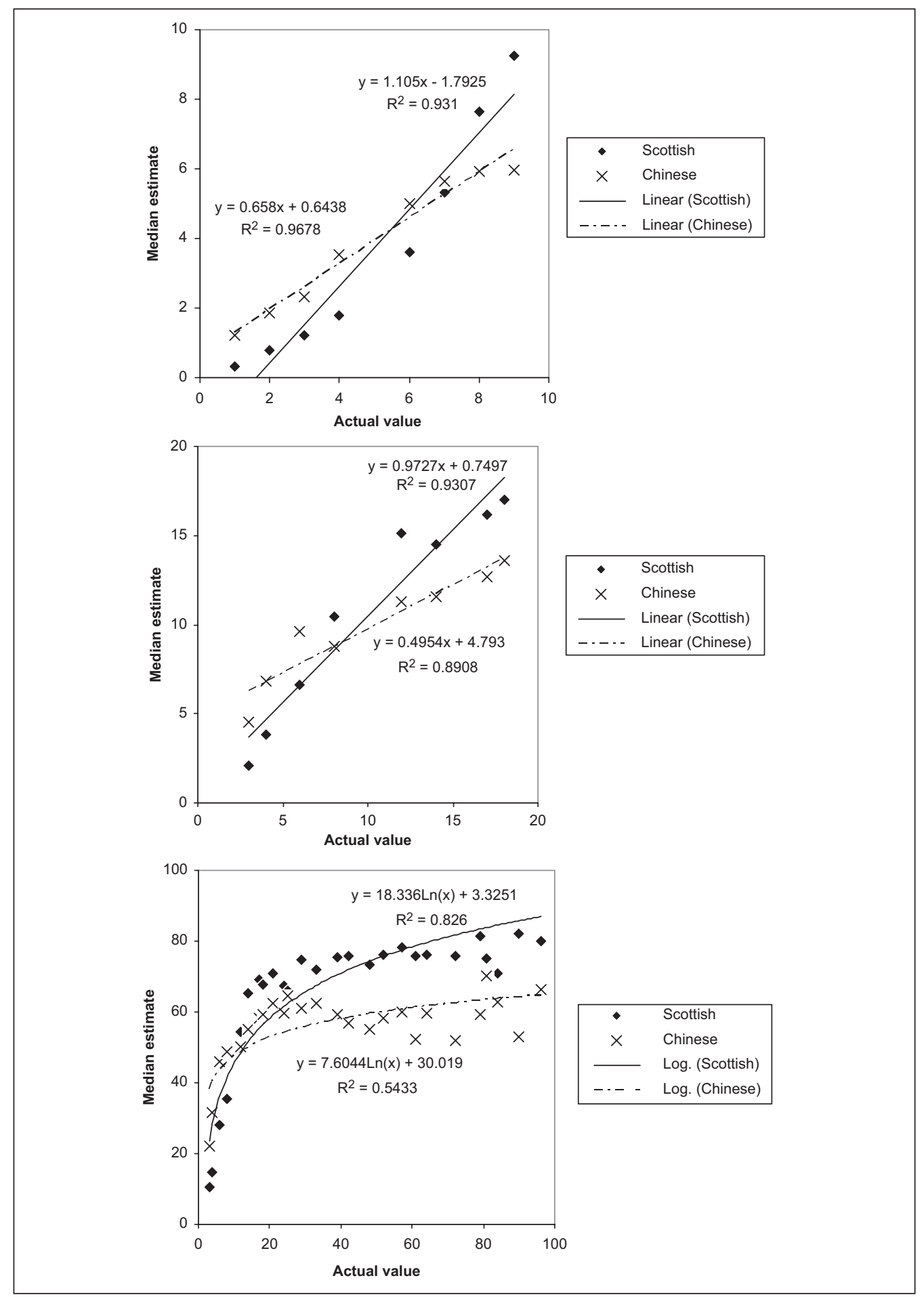

Figure 2. U.K. and Chinese (BAS-Matched) Median Estimates for 0 to 10,0 to 20, and 0 to 100 Number Lines Showing Linear (0 to 10,0 to 20) and Logarithmic (0 to 100) Function Fits 
slope in excess of 1) for numbers with which they are more familiar. In contrast, the absence of a magnitude effect above this range converges with the interpretation that many were simply guessing. We did not find a breakpoint that demarcated single versus multi-digit numbers.

BAS-matched samples. The analyses reported so far are based on the full cohort. Since the Scottish and Chinese were not exactly equated on BAS scores, we created subsamples with a better match. Removing those Chinese children with a BAS ability score of 105 or less (approximately $1.5 S D$ below the mean) yielded a Chinese ${ }_{\text {BAS-match) }}$ group of 58 children (mean age 55 months, range $=47$ to 62 months) with a mean BAS score of 131 (range $=111$ to 170 ). We then selected at random 58 children (mean age 64 months, range $=57$ to 70 months) from the Scottish cohort to give us an equivalently sized matched comparison group; Scottish (BAS-match) $_{\text {(mean }}$ BAS score $=133$, range $=88$ to 170 ). Removing the lowest performing Chinese children resulted in there being no significant difference between the two samples on any of the five BAS subcategories.

Number estimation task. The Scottish subsample remained more accurate on the 0 to 10 number line, $t(114)=-3.56, p<.001$, and on the 0 to 20 line, $t(114)=-5.01, p<.001$, but not on the 0 to 100 number line, $t(96)=-.92, p>.05$. Similarly, the slopes of the Scottish (BAS-match) $_{5.10}$ estimates were closer to 1.00 than the Chinese ${ }_{\text {(BAS-match) }}$ estimates on the 0 to 10 line, $t(114)=5.80, p<$ .001 , on the 0 to 20 line, $t(114)=6.30, p<.001$, but not on the 0 to 100 line, $t(96)=-.90, p>.05$. Mirroring analyses above, this pattern of effects held true when BAS ability scores and age were entered separately as covariates.

National differences in mean $R_{\text {lin }}^{2}$. Again, these results (see Figure 2) were consistent with the earlier set of analyses; the variance accounted for by the linear function was greater for the Scottish $_{\text {(BAS-match) }}$ than the Chinese (BAS-match) $_{\text {an }}$ on to 10 scale, $t(114)=3.42, p<.01$, and the 0 to 20 scale, $t(159)=3.78, p<.001$, but there was no significant difference on the 0 to 100 scale. All three results held after entering separately BAS ability score and age in months as covariates.

Association between number line estimation and mathematical skill. The correlations between the BAS ability scores by the Chinese ${ }_{\text {(BAS-match) }}$ children and the linearity of their estimations was almost identical to the results using the full Chinese cohort. However, using PAE values, the correlation on the 0 to 10 line is clearly significant and approaches significance on the 0 to 100 line; contrary to expectation, there was a positive association between error rate and BAS for the Chinese $_{(\text {BAS-match) }}$ children on this scale.

We again investigated whether linearity of estimations was more closely associated with particular categories (see Table 6). As with the full Chinese sample, the linearity of children's estimations was most consistently correlated with "recognizing numerals" and "identifying quantitative relationships."

Comparing the full Chinese cohort with the matching sample. The raising of the mean BAS ability score by removing the lowest scoring children begs the question of whether the change results in these remaining children having more linear and more accurate estimations than the full cohort. Comparing the two Chinese groups ("Chinese" and "Chinese BAS-match"- see Tables 1 and 2) reveals that removing the children with the lowest BAS scores resulted in only moderately lower PAE rates (on 0 to 10 and 0 to 20 scales) and no decrease at all on the 0 to 100 scale. Just as importantly, it resulted in similarly modest, nonsignificant increases in $R^{2}$ lin on the 0 to 10 and 0 to 20 number lines and no increase at all on the 0 to 100 scale. When examining the BAS-matched data for bi-linear function fits, the breakpoints were similar to those found using the full cohort; for the Scottish children, the breakpoint around 15 on the 0 to 100 scale was reflected in slope values of $4.9 / 0.13$, whereas the Chinese data yielded slope values of $2.53 /<.01$ (with slope values of 1.66/0.45 for target numbers below/above 7 on the 0 to 20 scale). 


\section{Discussion}

We were surprised to see that our Scottish cohort was better on the BAS problems than the full Chinese cohort given findings in cross-cultural comparisons of math ability and the fact that the Chinese cohort was higher in terms of percentile ranking than the Scottish cohort. Geary, BowThomas, Fan, and Siegler (1996) noted that Chinese children display an advantage over American children in simple arithmetic in the first months of schooling, before differences in teaching could easily account for such an advantage. ${ }^{2}$ Geary et al. (1996) suggest that the differences are probably accounted for by increased processing speed and better counting skills. Another key difference could be the quality of children's representations of numbers, as suggested by Siegler and $\mathrm{Mu}$ (2008). The present study broadens this landscape, and the results reveal a more complex picture of development.

There is more to number knowledge than how to answer addition problems, particularly when discussing younger children (children in the Geary et al., 1996, and Siegler \& Mu, 2008, studies were between 67 and 71 months on average). For the age range we looked at (47 to 70 months), it was evident that performance on number estimation tasks was most closely associated with problems of mapping (between numerosities and numerals) and matching. In contrast, estimation skill was less strongly correlated with addition problems, in particular for the two ability matched groups. The different correlation values - both within and between nationalities - for the five BAS subcategories confirm that not all math tasks are equivalent in their association with numerical estimation skill.

Similarly, the use of different scales reveals the potential richness of data that can be obtained. We can now engage with the notion that the link between estimation performance and mathematical ability might be scale-dependent. If the developmental trajectory of estimation skills is to be properly identified, it becomes important to match a particular age group with relevant mathematical problems and use multiple number scales. We found that the linear function fits for the Scottish children on the 0 to 10 number line were approaching ceiling, whereas relatively few children displayed a linear profile on the 0 to 100 line. Indeed, evidence for a bi-linear model of estimation on this scale suggests that children were applying a strategy that yielded a magnitude effect for familiar numbers only (the breakpoint was at 15, and not 10 as would be expected if the crucial distinction was between single and double-digit numbers). In contrast, in the younger Chinese group, we did find a correlation between estimation linearity and math performance on the smallest number scale. This was the case even when the two groups had been ability matched. It is probable that there are multiple associations between the quality of numerical estimations on different number scales with different age groups, but most of these have yet to be identified. It will be important to look in more detail at the points of intersection between numerical magnitude concepts and math cognition (and the cross-cultural consistencies) to the extent that they exist.

\section{Does Greater Estimating Ability Lead to Better Math Performance?}

Was the advantage the Scottish children exhibited due to them drawing on better quality representations of number? The Scottish cohort's estimations were better fit by a linear function and were more accurate on the two smaller number scales (the range of numbers required to answer nearly all questions on the BAS). However, the Scottish children were older, as well as being more proficient (in absolute terms) on the standardized math assessment. Ensuring an ability match between the two groups served to throw light on this issue. While the matched Chinese sample inevitably had higher BAS scores than the full Chinese sample, there were no significant concomitant increases in either the linearity or the accuracy of this group's estimations. Following Siegler and Mu (2008), one should predict an increase in math performance reflected 
in the quality of children's estimations, but this was not the case. Not only is the link between number estimation and mathematical ability not global, it appears to be weaker than previously reported. Importantly, the notion that non-linear representation of numerals has a causal impact on mathematical development is not supported.

It remains to be seen how establishing whether children's representations of larger numbers are logarithmic or bi-linear will impact on the associations we found here. What does seem clear is that by extending the range of number tasks, using multiple number line scales, obtaining longitudinal data, and comparing cross-culturally, it should be possible to establish where, when, and why such associations are to be found. We present the case that the quality of children's representations of number might be important for some early numeracy targets but are unlikely to be crucial for others and emphasize the value of investigating further the cognition underlying the developmental trajectories in school-based mathematical activities.

\section{Acknowledgments}

We would like to thank the staff and children of Blackhall Primary School, Gylemuir Primary School, Fox Covert RC Primary School, Roseburn Primary School, and St. Peter's Primary School, Edinburgh, for their generosity and commitment to this project. In China, we would like to thank the 2nd Nankai Kindergarten, the 16th Hexi Kindergarten, and the 19th Hedong Kindergarten (Tianjin) for the same. We thank Korbinian Moeller for suggesting the SegReg programme. We thank the Economic and Social Research Council, UK, for funding the research (Grant RES-062-23-0970).

\section{Declaration of Conflicting Interests}

The author(s) declared no potential conflicts of interest with respect to the research, authorship, and/or publication of this article.

\section{Funding}

This work was supported by a grant awarded to Muldoon and Towse by the Economic and Social Research Council (ESRC) (Grant RES-062-23-0970).

\section{Notes}

1. Some children did not receive the 0 to 100 number line task due to displays of fatigue.

2. It is not clear at this stage why we did not find more evidence for precociousness among the Chinese children. One possibility is that the Chinese sample was not fully representative of their age group. Nonetheless, it is important to keep in mind that a core aim here is to study ability matched samples, which we were able to do.

\section{References}

Booth, J. L., \& Siegler, R. S. (2006). Developmental and individual differences in pure numerical estimation. Developmental Psychology, 41, 189-201.

Booth, J. L., \& Siegler, R. S. (2008). Numerical magnitude representations influence arithmetic learning. Child Development, 79, 1016-1031.

Bradley, L., \& Bryant, P. E. (1978). Difficulties in auditory organisation as a possible cause of reading backwardness. Nature, 271, 746-747.

Cain, K., Oakhill, J. V., \& Bryant, P. E. (2000). Investigating the causes of reading comprehension failure: The comprehension-age match design. Reading and Writing, 12, 31-40.

Dehaene, S. (1997). The number sense: How the mind creates mathematics. New York: Oxford University Press.

Ebersbach, M., Luwel, K., Frick, A., Onghena, P., \& Verschaffel, L. (2008). The relationship between the shape of the mental number line and familiarity with numbers in 5- to 9-year old children: Evidence for a segmented line. Journal of Experimental Child Psychology, 99, 1-17. 
Fischer, M. (2003). Spatial representations in number processing: Evidence from a pointing task. Visual Cognition, 10, 493-508.

Geary, D. C., Bailey, D. H., \& Hoard, M. K. (2009). Predicting mathematical achievement and mathematical learning disability with a simple screening tool: The number sets test. Journal of Psychoeducational Assessment, 27, 265-279.

Geary, D. C., Bow-Thomas, C. C., Fan, L., \& Siegler, R. S. (1996). Development of arithmetical competencies in Chinese and American children: Influence of age, language, and schooling. Child Development, 67, 2022-2044.

Nuerk, H. C., Kaufmann, L., Zoppoth, S., \& Willmes, K. (2004). On the development of the mental number line: More, less, or never holistic with increasing age? Developmental Psychology, 40, 1199-1211.

Oosterbaan, R. J. (n.d.). Introduction to the SegReg program. Available at www.waterlog.info

Siegler, R. S., \& Mu, Y. (2008). Chinese children excel on novel mathematics problems even before elementary school. Psychological Science, 19, 759-763.

Siegler, R. S., \& Opfer, J. E. (2003). The development of numerical estimation: Evidence for multiple representations of numerical quantity. Psychological Science, 14, 237-243.

Stevenson, H. W., Chen, C., \& Lee, S.- Y. (1993). Mathematics achievement of Chinese, Japanese and American children: Ten years later. Science, 259, 53-58.

Torbeyns, J., Verschaffel, L., \& Ghesquière, P. (2004a). Strategic aspects of simple addition and subtraction: The influence of mathematical ability. Learning and Instruction, 14, 177-195.

Torbeyns, J., Verschaffel, L., \& Ghesquière, P. (2004b). Strategy development in children with mathematical disabilities. Journal of Learning Disabilities, 37, 119-131.

Towse, J. N., \& Saxton, M. (1998). Mathematics across national boundaries: Cultural and linguistic perspectives on numerical competence. In C. Donlan (Ed.), The development of mathematical skills (pp. 129-150). Hove, UK: Psychology Press.

\section{Bios}

Kevin Muldoon is a lecturer in psychology in the School of Life Sciences at Heriot Watt University, Edinburgh where he has studied early number development since 2004.

Victoria Simms is a Research Fellow at Queen's University, Belfast, where she pursues her interest in the development of young children's reasoning skills.

John Towse is a senior lecturer in the Department of Psychology at Lancaster University where he has worked since 2001. He has several research interests than span cognitive and developmental psychology, but with a long-standing interest in understanding the development of mathematical cognition.

Victoria Menzies is currently studying for a $\mathrm{PhD}$ at the University of York, exploring the effects of peer tutoring on maths learning at Primary school level.

Guoan Yue is Professor of Psychology at Nankai University, Tianjin, China. He holds various professional positions including Vice President of the Chinese Psychological Society and President of the Chinese Association of Social Psychology. 